REGARDS

SUR L'ECONOMIE ALLEMAND

BULLETIN ECONOMIQUE DU CIRAC
Regards sur l'économie allemande

Bulletin économique du CIRAC

$92 \mid 2009$

Varia

\title{
Salaires : plus forte hausse en France depuis 2005
}

Isabelle Bourgeois

\section{CpenEdition}

Journals

Édition électronique

URL : http://journals.openedition.org/rea/3769

DOI : 10.4000/rea.3769

ISBN : 978-2-8218-0880-5

ISSN : 1965-0787

Éditeur

CIRAC

Édition imprimée

Date de publication : 1 juillet 2009

Pagination : 35-36

ISSN : 1156-8992

Référence électronique

Isabelle Bourgeois, «Salaires : plus forte hausse en France depuis 2005 », Regards sur l'économie allemande [En ligne], 92 | juillet 2009, mis en ligne le 01 juillet 2011, consulté le 15 septembre 2020. URL : http://journals.openedition.org/rea/3769

Ce document a été généré automatiquement le 15 septembre 2020.

(C) CIRAC 


\title{
Salaires : plus forte hausse en France depuis 2005
}

\author{
Isabelle Bourgeois
}

1 De 2007 à 2008, les salaires conventionnels mensuels ont augmenté en moyenne de $2,8 \%$ en Allemagne, mais de 3,1 \% en France. Pour la cinquième année consécutive, la progression des salaires a été plus faible outre-Rhin, alors que dans le même temps, celle de l'indice des prix à la consommation restait identique $(+2,8 \%)$. C'est ce qu'il ressort d'une étude conjointe réalisée par Destatis et l'Insee.

2 Dans les deux pays, la hausse des salaires a été plus forte en 2008 qu'au cours des années précédentes, et tout particulièrement au premier semestre de l'année. La plus faible progression au cours de $2^{\mathrm{e}}$ semestre a des causes différentes: outre-Rhin, entraient alors en vigueur le plus souvent les deuxièmes volets des conventions tarifaires conclues dans les principales branches en 2007, voire avant, et qui prévoyaient des hausses moins fortes (les hausses négociées étaient généralement échelonnées sur l'ensemble de la durée de la convention). En France, par contre, le ralentissement relatif constaté au $2^{\mathrm{e}}$ semestre était dû aux premières répercussions de la crise financière. Si le niveau des hausses salariales varie grandement entre les différentes branches, à la fois au sein de chacun des pays, comme en comparaison des deux, une des principales raisons à la forte différence constatée au $2^{\mathrm{e}}$ semestre dans le commerce $(+3,1 \%$ en moyenne en France contre $+2,0 \%$ en Allemagne) est due à la hausse du SMIC horaire au $1^{\mathrm{er}}$ juillet : il était alors passé à $8,71 €$ (soit une hausse de 3,2\%). En Allemagne, un SMIC légal n'existe actuellement que dans cinq métiers du BTP, dans le secteur de la propreté (BTP) et dans celui des services postaux (il y avait été instauré le $1^{\mathrm{er}}$ janvier 2008 ; voir REA 85/08). (IB)

Progression des salaires conventionnels par branche en France et en Allemagne 2005-2008 (en \%)

\begin{tabular}{|l|l|l|l|l|l|l|l|l|}
\hline Branche & \multicolumn{4}{|l|}{ Allemagne } & \multicolumn{3}{l|}{ France } \\
\hline & 2005 & 2006 & 2007 & 2008 & 2005 & 2006 & 2007 & 2008 \\
\hline
\end{tabular}




\begin{tabular}{|l|l|l|l|l|l|l|l|l|}
\hline Secteur minier et extraction de minéraux & 0,9 & 0,3 & 0,9 & 3,6 & 2,8 & 2,7 & 2,5 & 3,1 \\
\hline Industrie & 1,5 & 2,3 & 3,2 & 3,0 & 2,7 & 2,7 & 2,7 & 3,1 \\
\hline Eau et énergie & 0,9 & 0,6 & 1,3 & 4,5 & 2,6 & 2,8 & 2,0 & 4,0 \\
\hline BTP & 0,0 & 1,1 & 1,5 & 3,0 & 3,6 & 3,2 & 3,2 & 3,3 \\
\hline Commerce (dont entretien automobile) & 1,0 & 1,0 & 1,6 & 2,0 & 3,0 & 2,8 & 2,6 & 3,1 \\
\hline Transports et communications & 1,4 & 1,3 & 1,7 & 2,1 & 2,6 & 3,1 & 2,7 & 3,0 \\
\hline Banque et assurance & 1,4 & 1,2 & 1,6 & 2,7 & 2,0 & 2,4 & 2,4 & 2,9 \\
\hline Toutes branches confondues & 1,2 & 1,6 & 2,3 & 2,8 & 2,8 & 2,8 & 2,7 & 3,1 \\
\hline Indice harmonisé des prix à la consommation & 1,9 & 1,8 & 2,3 & 2,8 & 1,8 & 1,6 & 1,5 & 2,8 \\
\hline
\end{tabular}

Source des données : Destatis, Pressemeldung nº 237 (26-06-2009).

INDEX

Mots-clés : salaire, revenu, niveau de vie, comparaison franco-allemande, France, Allemagne 